\title{
Indian Perspective about Advertising Appeal
}

\author{
Anil Mishra \\ Department of Marketing and Retail \\ Indore Management Institute and Research Centre \\ Near Chokhi Thandi, Khandawa Road \\ Indore, M.P, India \\ Tel: 91-9425-452-065 E-mail: doctorani197@rediffmail.com
}

\begin{abstract}
Everyday consumers are bombarded with different advertising campaigns but they do not respond as they need something other than tangibles. There is need to explore something more than tangibles that can attract their attention. This can be done by using appropriate advertising appeal in the advertising campaign. If advertising appeal is interesting then it grabs the attention of the customers. For the present study survey method was used. It was done in two stages; in first stage initial questionnaire was prepared and implemented on 50 judges and after analyzing this data final questionnaire was prepared and was implemented on 200 respondents in the age group of 18-25 years. Findings of the study revealed that persuasiveness, distinctness, perfectness, fascinating, sensational, energetic, aesthetic, elegant and captivating were the factors that emerged for the advertising appeal and dimensions were energetic, sensational, persuasiveness, distinctness and captivating. Factor and dimensions were compared on the basis of gender. It was found that persuasiveness, perfectness, sensational factors and energetic, sensational and persuasiveness dimensions do not vary on the basis of gender as males and females both felt that these factors and dimensions were important but females perceived that distinctness factor and dimension and aesthetic factor is more important than males but for males fascinating factor was more important than the females.
\end{abstract}

Keywords: Advertising appeal, Advertising campaign

\section{Introduction}

Advertising appeal gives a reason to buy a product. An advertising campaign may have one or more advertising appeal. One appeal can be used and it can have sub themes in an advertising campaign. Appeal needs to be unique and needs to give positive impression about the product to the target audience. Every appeal that is used by the companies in the advertising is as per their competitors. Another important aspect of appeal is that it needs to be believable by the audience (Kumar, 1998). Audience gets attentive when the advertisement is there, they try to comprehend it and then finally their purchase behavior is inclined towards the brand. When audience behavior is molded by the advertiser towards the brand then only their purpose of advertisement is achieved. In order to do so advertisers understand the psychological aspects of the audience and then they try to develop the advertising appeal which can change their attitude towards the brand.

For advertiser it is very important to understand how the diffusion of the message that takes place in the target audience and in order to have a positive diffusion advertiser creates a favorable environment. Words play an important role in the advertising message as it directly affects the mind of the target audience. Psychologist feels that all the human activities are based on the needs (Lamb et al., 1992, Schewe, 1987). Consumers may have different types of needs like physiological, physical or latent. An individual who has a specific need always look for the information from the marketing world. When there is cue which is as per the need of the consumer then an individual responds for the product. Drivers that are present in an individual vary at the different levels. Consumer may be inclined towards the product because of the aura of prestige which is associated with the advertising appeals.

Advertising appeal is the main central message in the advertising message. It arouses the desires and addresses the human need that can be satisfied by the product which is advertised. Appeal is the underlying content in the advertising. Advertising appeal and execution are usually interdependent but advertising appeal can be used in all types of media but the execution style is different for different type of media. Advertising appeal is that something which attracts the consumers and develops interest in them. Some common consumer appeals are esteem, sex, fear, security and sensory 
pleasure. Advertiser uses the word appeal to emphasis on the creativity. Advertising create desire for the product and appeals persuade the consumer to invest in the product. Appeals not always have all the product attributes but they create an atmosphere where the target audience desires are evoked towards the product. For example, if there is a product for the housewives then the appeal would be related to family.

\section{Review of Literature}

There are mainly two types of appeals rational and emotional appeals. Rational appeal addresses the consumer's functional needs of the product. Kotler (2000) opined that rational appeal is based on logic and product are been sold by highlighting the product attributes, quality, its problem solving capacity and its performance. Rational appeals are informative in nature and it focuses on the suitability of the product. This appeal is used by consumer durables and in competitive advertising. There are different types of rational appeal like feature appeal that focuses on important traits and features of the product. Information content in such kind of advertisement is very rich. It is used by high involvement product. There is another type of appeal named as competitive advantage appeal which gives a comparative picture of two or more brands. Comparison can be direct or indirect depending upon the brand and the product category. Price appeal is another type of rational appeal which focuses on the price or value of the product. This appeal is also used during the festival season. News appeal is used when a new product is introduced in the market or if certain modifications are done in the existing products. When the message is to be communicated to a larger audience and it is the established brand then popularity appeal is used as it emphasizes on the experience of the satisfied consumers.

Rational appeals are based on the logic and reason to buy to product. In the actual scenario both the appeals i.e., rational and emotional appeals works together. Emotional appeals are woven with the sensation of fun, love, enjoyment, fear etc (Ramaswamy and Namakumari, 2002). Kotler (2000) opined that there could be positive emotions as well as negative emotions but in the advertising campaign negative emotions can be converted to positive emotions. Emotional appeal is the feeling associated with the product. There are certain dreams and hope which are present in the individual which works consciously or subconsciously and gives pleasant feeling in the individual's psyche. Emotions also help in arousing and directing the behavior of an individual (Morris, 1999).

Emotions also affect the consumer's memory. When the state of mind is excited or agitated then it prompts the consumer to buy the product (Chunawalla et al, 1998). Therefore, emotional appeals are known as transformational appeals as they transform the feelings of the consumers towards the product. It gives positive mood to the consumers as it is related to the psychological attribute of the consumer. Emotional appeals are more effective for the older market then the newer or the younger market.

When the emotional appeals are used in the advertising then consumption pattern of the product is very enjoyable. Sex appeal is used in the advertisement of soaps Audience is attracted as the desire is evoked and then it helps in selling the product. Sex appeal mainly helps in attracting the opposite gender masculine or feminine (Wright, 2000). According to Bradley (1995) sex appeal considered to be an offence sometimes depending upon the culture and the country but if the sex appeal is not obscene then it is acceptable in the society. For the perfumes and cosmetics love appeal is used. These appeals are used more younger generation.

\section{Objective of the Study}

The primary objective of the study is to understand the dimensions of advertising appeal. The study also aims to study the concept of advertising appeal in consumer durables. The study tries to explore the consistency in the perception of the respondents across demographic variable of gender. The study is undertaken to distinguish between the dimensions of advertising appeal and its effects on consumers. The study aimed at the development of a specific framework of advertising appeal for consumer durable.

\section{Methodology}

The present investigation is an exploratory study undertaken to identify the dimensions of advertising appeal. The study was carried out with a multi-stage to understand the perceptions of the users about the appeal of an advertisement. The extraneous variables, such as casual responses, faking, culture, urban / rural background, educational background, family income and professional and non- professional education were controlled by randomization and elimination. The list of 128 appeal attributes developed on the basis of review of literature was screened to eliminate repetition, synonyms and attributes unrelated to appeal. Only those attributes were retained, which were likely to be associated with the appeal of inanimate product. A sample of 50 judges was shown the definition of advertising appeal framed after review of relevant literature. The list of 50 advertising appeal attributes having 75 percent and above acceptance was retained (refer Appendix 1). Questionnaire was prepared based on these attributes, then it was administered on the final sample of 200 respondents who were students in the age group of 18-25 years. The sample had a bivariate distribution in terms of gender. 
The item-total correlation of the attributes is computed (refer Appendix 2). In first iteration 27 items are found insignificant therefore they are eliminated. In second iteration, 23 attributes are significant and are retained (level of significance being 0.05 ). They are significantly correlated with the total score. Further, to identify the factor pertaining to durable product, factor analysis is undertaken (refer Appendix 3,5). Second order factor analysis is employed to identify the dimensions of advertising appeal of consumer durable (refer Appendix 4, 6). 23 variables converged into 9 factors and then it converged into 9 dimensions. SPSS (version 14) software was used for the data analysis. Factors and dimensions were compared on the demographic variable of gender by using z-test (refer Appendix 7, 8).

The external validity and generalized ability of a psychometric measure depends upon the subjects on which the study is conducted. Keeping this in focus, a sample of the ad viewers was chosen. The simple random method of sampling was applied to collect data from the initial sample, which after screening for response error was retained for final analysis. The sample was collected from various professional and non-professional institutions. The respondents were exposed to the print advertisements (bike) and were asked to fill up the questionnaire. All subjects were well versed with English besides being multilingual. Thus, after ensuring the content validity of the items selected, the reliability of the questionnaire was determined by split-half method corrected for full length by applying Spearman Brown Prophecy formula on the data collected from the sample of 200 subjects in each category. The reliability coefficient was .91212 . The assessment of advertising appeal of the product categories, and its validity was taken equivalent to reliability index i.e., 0.95505 .

\subsection{Results of the Study}

(A)Factors

Factors that were emerged for advertising appeal were persuasiveness, distinctness, perfect ness, fascinating, sensational, energetic, aesthetic, elegant and captivating.

4.1.1 Proposition 1: Persuasiveness $=\mathrm{f}($ Gender * Product Category

Problem 1: Is $(\mathrm{a})_{\mathrm{bp}}=(\mathrm{b})_{\mathrm{bp}}$

Wherein (a $)_{b p}$ is Persuasiveness as perceived by males in the case of bike.

$(b)_{b p}$ is Persuasiveness as perceived by females in the case of bike.

$H_{01}$ : Males and females do not differ on the factor of Persuasiveness in the case of advertisements of bike.

$H_{01}$ stands accepted $(\mathrm{z}=0.55545)$.

4.1.2 Proposition $2:$ Distinctness $=\mathrm{f}($ Gender $*$ Product Category $)$

Problem 2: Is $(\mathrm{a})_{\mathrm{bd}}=(\mathrm{b})_{\mathrm{bd}}$

Wherein $(a)_{b d}$ is Distinctness as perceived by males in the case of bike.

(b) $)_{\text {bd }}$ is Distinctness as perceived by females in the case of bike.

$H_{02}$ : Males and females do not differ on the factor of Distinctness in the case of advertisements of bike.

$H_{02}$ stands rejected $(\mathrm{z}=2$.61593). Thus, females perceive the factor of Distinctness more in the advertisements of bike in comparison to the males.

4.1.3 Proposition 3: Perfectness $=\mathrm{f}($ Gender * Product Category $)$

Problem 3: Is $(\mathrm{a})_{\mathrm{bpr}}=(\mathrm{b})_{\mathrm{bpr}}$

Wherein $(a)_{b p r}$ is Perfectness as perceived by males in the case of bike.

(b) $)_{\text {bpr }}$ is Perfectness as perceived by females in the case of bike.

$H_{03}$ : Males and females do not differ on the factor of Perfectness in the case of advertisements of bike.

$H_{03}$ stands accepted $(\mathrm{z}=1.46395)$.

4.1.4 Proposition 4: Fascinating $=\mathrm{f}($ Gender $*$ Product Category $)$

Problem 4: Is $(a)_{b f}=(b)_{b f}$

Wherein $(a)_{b f}$ is Fascinating as perceived by males in the case of bike.

(b) bf $_{\text {is }}$ Fascinating as perceived by females in the case of bike.

$H_{04}$ : Males and females do not differ on the factor of Fascinating in the case of advertisements of bike.

$H_{04}$ stands rejected $(\mathrm{z}=11.8569)$. Thus, males perceive the factor of Fascinating more in the case of advertisements of bike than females. 
4.1.5 Proposition 5: Sensational $=\mathrm{f}($ Gender * Product Category $)$

Problem 5: Is $(\mathrm{a})_{\mathrm{bs}}=(\mathrm{b})_{\mathrm{bs}}$

Wherein $(a)_{b s}$ is Sensational as perceived by males in the case of bike.

(b) bs is Sensational as perceived by females in the case of bike.

$H_{05}$ : Males and females do not differ on the factor of Sensational in the case of advertisements of bike.

$H_{05}$ stands accepted $(\mathrm{z}=0.1229)$.

4.1.6 Proposition 6: Energetic $=\mathrm{f}($ Gender * Product Category $)$

Problem 6: Is $(\mathrm{a})_{\mathrm{be}}=(\mathrm{b})_{\mathrm{be}}$

Wherein $(a)_{b e}$ is Energetic as perceived by males in the case of bike.

(b) be is Energetic as perceived by females in the case of bike.

$H_{06}$ : Males and females do not differ on the factor of Energetic in the case of advertisements of bike.

$H_{06}$ stands accepted $(\mathrm{z}=0.75827)$.

4.1.7 Proposition 7: Aesthetic $=\mathrm{f}($ Gender * Product Category $)$

Problem 7: Is $(\mathrm{a})_{\mathrm{ba}}=(\mathrm{b})_{\mathrm{ba}}$

Wherein (a) $)_{b a}$ is Aesthetic as perceived by males in the case of bike.

(b) $)_{\mathrm{ba}}$ is Aesthetic as perceived by females in the case of bike.

$H_{07}$ : Males and females do not differ on the factor of Aesthetic in the case of advertisements of bike.

$H_{07}$ stands rejected $(\mathrm{z}=2.01541)$. Thus, females perceive the factor of Aesthetic more in the case of advertisements of bike in comparison to the males.

(B) Dimensions

Results of the second order factor analysis revealed that there were four dimensions, they were Energetic, Sensational, Persuasiveness and Distinctness.

4.1.8 Proposition 8: Energetic $=\mathrm{f}($ Gender * Product Category $)$

Problem 8: Is $(\mathrm{a})_{\mathrm{bE}}=(\mathrm{b})_{\mathrm{bE}}$

Wherein $(a)_{b E}$ is Energetic as perceived by males in the case of bike.

(b) $)_{\mathrm{bE}}$ is Energetic as perceived by females in the case of bike.

$\mathrm{H}_{08}$ : Males and females do not differ on the dimension of Energetic in the case of advertisements of bike.

$H_{08}$ stands accepted $(\mathrm{z}=0.9883)$.

4.1.9 Proposition 9: Sensational $=\mathrm{f}($ Gender * Product Category $)$

Problem 9: Is $(\mathrm{a})_{\mathrm{bS}}=(\mathrm{b})_{\mathrm{bS}}$

Wherein $(a)_{b s}$ is Sensational as perceived by males in the case of bike.

(b) $)_{b \mathrm{~S}}$ is Sensational as perceived by females in the case of bike.

$H_{09}$ : Males and females do not differ on the dimension of Sensational in the case of advertisements of bike.

$H_{09}$ stands accepted $(\mathrm{z}=1.1723)$.

4.1.10 Proposition 10: Persuasiveness $=\mathrm{f}($ Gender $*$ Product Category $)$

Problem 10: Is $(\mathrm{a})_{\mathrm{bP}}=(\mathrm{b})_{\mathrm{bP}}$

Wherein $(a)_{b P}$ is Persuasiveness as perceived by males in the case of bike.

(b) $)_{\mathrm{bP}}$ is Persuasiveness as perceived by females in the case of bike.

$H_{010}$ : Males and females do not differ on the dimension of Persuasiveness in the case of advertisements of bike.

$H_{010}$ stands accepted $(\mathrm{z}=0.55545)$.

4.1.11 Proposition 11: Distinctness $=\mathrm{f}($ Gender $*$ Product Category $)$

Problem 11: Is $(\mathrm{a})_{\mathrm{bD}}=(\mathrm{b})_{\mathrm{bD}}$

Wherein $(a)_{b D}$ is Distinctness as perceived by males in the case of bike.

$(b)_{\mathrm{bD}}$ is Distinctness as perceived by females in the case of bike. 
$H_{011}$ : Males and females do not differ on the dimension of Distinctness in the case of advertisements of bike.

$H_{011}$ stands rejected $(\mathrm{z}=2.61593)$. Thus, females perceive the dimension of Distinctness more in the advertisements of bike in comparison to the males.

\section{Discussion}

Persuasiveness is a factor and a dimension that has emerged for the advertisement of bike. Males and females do not differ on the factor and dimension of Persuasiveness in the case of advertisements of bike. Choudhary (2004) explains that the nature of the product advertised plays a key role in determining the amount of cognition required to process an advertising message. Specifically, the amount of perceived risk associated with purchase pre-determines the level of interest given to a product's message.

Bike has a higher perceived risk and hence the degree of involvement is more in bike. Schiffman (2004) wrote that it is degree of involvement in product category that calls for persuading the target audience. Bradly (1995) wrote that women are more emotional than men and thus more responsive to emotional appeal but the results of the present study show that there is no difference between males and females regarding the basis of shaping the action and judgment. Consumers process the message logically before emotional values are transferred. Choudhary (1998) studies on luxury and necessity items have yielded information on the relationship between high-involvement and low-involvement products, perceived risk and emotional experience. High-involvement purchase decisions often involve high levels of perceived risk, sending consumers into a state of increased information search.

Distinctness was found to be a factor as well as a dimension for the advertisements of bike. The ads that are stylish and imaginative are able to have clear-cut impact on the respondent's memory and can be termed as unique. Advertisements that are unique can make space in memory of the respondents easily as compared to those ads, which are routine in nature. Best ads are unique and original. The buyers are exposed to a world of information. They may ignore certain pieces of information and actively seek out some other information. Further, they may merely overhear some message and may register in the mind. In other words buyers filters the information and tends to perceive events more easily as representatives of categories rather than unique and idiosyncratic. Therefore, it becomes important that cues in the consumers identification, categorization and perception of products must be given due emphasis. Petova and Cialdini (2005) concluded that marketers need to take their brands' imprints beyond the commonly used senses of sight and sound, and capitalize on the stronger impact. Males differ from females in their perception about distinctness factor and dimension in the advertisements of bike. Females perceive distinctness factor and dimension more in the advertisements of bike which can be attributed to the fact that females do not have first hand experience of operating the bike. They feel to have higher involvement in bike therefore, feel advertisements for bike should be distinct.

Perfect advertisements are completing not deficient or faultless. Complete event or action is capable of inducing fun and excitement while conveying the underlined message. Perfectness has emerged as a common factor in the advertisements of bike. However, males and females both perceived that perfect ness factor is important in the advertisements of bike. The essential point in perception is that whole is different from the sum of its parts. In other words, the whole carries a different and altogether greater meaning than its individual components. In viewing the whole, a cognitive process takes place the mind makes a leap from comprehending the parts to realizing the whole. Gestalt theory proposed that the operational principle of the brain is holistic, parallel, and analog, with self-organizing tendencies. The Gestalt effect refers to the forming capability of our senses, particularly with respect to the visual recognition of figures and whole forms instead of just a collection of simple lines and curves (Morris, 1993).

An advertisement is fascinating when it is a pleasant experience to watch and is accompanied with jest. It becomes exciting, irresistible attraction and worth remembering. Fascinating emerged as a common factor in the advertisements of bike. Males perceive that fascinating factor is more important in the case of advertisements of bike than females, the labeling of arousal depends on an attribution, which is the process of identifying the cause of some event.

Imagination involves the capability to think of possibilities. An unfettered freedom of expression beyond the limitation of what is known and believed breaks the established reality and can add to fascination. Reality environment seeks to elicit fantasies, as consumers blend fantasy with reality. These environments essentially thermatize the imaginary into desired form and facilitates in shifting the imagination among the consumers. Consumers focus attention on visual images and are a entranced in a thematized space (Martin, 2004). So, whenever there is a break from the established reality, the monotony is broken and the viewer is fascinated by the intuitive appeal.

Sensational emerged as a common factor and subsequently a common dimension in bike. If the advertisements are wonderful, the respondents are excited. Emotional motivation is at a sub-conscious level. Respondents prefer to believe that they make decisions based upon purely objective and observable criterion. Due to strong reaction their interest is evoked. Consumers prefer symbolic language and images that relate to their senses. They are far less receptive and responsive to language and images that relate to concepts as compared to symbolic language and images that express 
what they feel, see, hear, smell, or taste. The language and images used in advertising should therefore, make sense to the audience (Lahey, 1995).

Consumer interprets physical sensations within a specific context. When consumers have no immediate explanation for their arousal, they would label their feelings in terms of the thoughts available to them and identify external cues. This labeling determines the emotion that is felt. Women may be more apt than men to develop emotional sensitivity. At the same time, men traditionally play roles in which emotional expressivities are downplayed and even discouraged. Traditional societal expectations lead women to develop more emotionality and men more restrained emotional style. Females and males perceive sensational factor and dimension more in the advertisements of bike. That shows that the sensational factor and dimension of the advertisements is product specific and more effective for durables like bike.

Energetic emerged as a common factor and dimension in the advertisements of bike. Advertisements with energetic appeal are able to infuse emphatically the message they want to convey. They infuse the feelings of being lively, vigorous and brisk through underlying information. Aggressive and creative ads are powerful and innovative enough to force the respondents to think about the product. Psychologists have identified the most fundamental human feelings of surprise, enjoyment, and anger occurring in combinations, influencing one another and account for the diversity of human feelings. Subjects interpret environmental cues of happiness or angry situations and are accordingly aroused (Fernald and Fernald, 1999).

When arousal from one experience carries over to an independent situation, it is called transferred excitation. People remain physiologically aroused longer. If the person feels aroused, he or she would accurately attribute the arousal to the experience he has undergone. Males and females perceived energetic factor and dimension is important in the advertisements of bike. Energetic information was effective in durables and low market segment.

Aesthetic is related to beauty or appreciation of beauty. Advertisements, which have a beautiful artistic presentation, are attractive and memorable as they have lasting impact on the respondent's memory. It is a pleasurable experience for the respondents to watch such ads. Females perceived aesthetic factor more important in the advertisements of bike as compared to males, which can be attributed to the fact that females do not drive bikes, see it as an object to be admired. Past experiences are really involved in perception, and memory does give them a distinct place in consciousness.

Content of consciousness may have an element of beauty in it. The truth is called beautiful because it thrills the soul with a peculiar feeling. The character is beautiful if it is embodiment of an ideal. There is a sense of satisfaction felt from any information conveyed by the truth. This feeling of satisfaction in the objective presentation of any harmonious ideal constitutes aesthetic sentiment (Dewey, 1998).

Elegant is a factor that has emerged for the advertisements of bike. Advertisements that are marked with style and grace can grab the attention of the respondents as the charm for the product increases. Consumers develop relation with brands if they assign a personality to a brand. A brand may be bought of as a male, young, fun loving or adventurous person. The brands may be perceived as masculine or feminine, modern or old fashioned, timid, aggressive, or self assured. Based on an assessment of overt and covert stimuli in the advertising, audience determines the personality of the brand. The brand must satisfy themselves, friends and colleagues thus, styling and presentation do matter to them. Bearden et al (1995) revealed that lifestyle traits are more concrete in acquisition, use and disposition of goods and services.

Captivating is another factor and dimension for bike. Respondents are attracted towards captivating advertisements as these advertisements affect their emotions. The arousal of any particular set of needs at a specific moment may be caused by internal stimuli generated by emotional or cognitive processes, or by stimuli in the outside environment. Attention, therefore, is the first processing response that an advertising element should generate if it has to produce the right kind of perception(Dewey, 1998).

\section{Conclusion and Scope for Future Research}

Factors that were emerged were persuasiveness, distinctness, perfectness, fascinating, sensational, energetic, aesthetic, elegant and captivating. When second order factor analysis was done then the dimensions that were emerged were energetic, sensational, persuasiveness, distinctness and captivating. Factor and dimensions were compared on the basis of gender. There are 11 hypotheses that were developed out of which 7 were accepted. It was found that persuasiveness, perfectness, sensational factors and energetic, sensational and persuasiveness dimensions do not vary on the basis of gender as males and females both felt that these factors and dimensions are important in the advertisement of consumer durable. Females perceived that distinctness factor and dimension and aesthetic factor is more important in advertising appeal than males. Males perceived that fascinating factor is more important in the advertising appeal than the females.

The study indicated that consumers see the advertisements as a person therefore, demographic and psychographic traits are very important in developing the advertising appeal. Advertising appeal affects the level of trust and the kind of relationship that the consumer has with the product. Advertising appeal helps in positioning the product in the mind of the consumers. As per the finding of the study he advertising appeal works on the whole brain concept as the dimension 
are logical as well as emotional. Left brain works on the rational thinking and right brain works on the creative thinking therefore, while designing the advertising appeal it needs to be both. In this research work only one product category is considered, further research can be done while considering different product categories or services with various brands. In this project only one demographic variable is considered i.e., gender other socio-demographic variable like age, income, occupation education can also be considered for future research. Another study can be carried on where the correlation of the advertising appeal with the consumer behavior, emotions and attitude can be studied. The study can be expanded further in order to study the cross cultural effects.

\section{References}

Bearden, William; Ingram, Thomas and Laforge, Raymond. (1995). Marketing. $1^{\text {st }}$ Ed. USA: Irwin.

Bradley, Frank. (1995). Marketing Management. $1^{\text {st }}$ Ed. United Kingdom: Prentice Hall.

Choudhary, Himadri. (2004). Does involvement act directly on advertising formation? : Conceptual issues and empirical investigation in the Indian context, Vilakshan XIMB Journal of Management, 1(1), 29-35.

Chunawalla; Kumar; Sethia, Suchak. (1998). Advertising Theory and Practice. $4^{\text {th }}$ Ed. Mumbai: Himalaya Publishing House.

Dewey, John. (1998). Psychology. $1^{\text {st }}$ Ed. New Delhi: Vivek Thani Khel Sahitya Kendra.

Fernald, Dodge and Fernald, Peter. (1999). Psychology. $5^{\text {th }}$ Ed. Delhi: AITBS Publishers

Kotler, Philip. (2000). Marketing Management. $10^{\text {th }}$ Ed. New York: Free Press.

Kumar, Ramesh. (1998). Marketing Nuggets. $2^{\text {nd }}$ Ed. New Delhi: Vikas Publication House

Lahey, B. Benjamin. (1988). Psychology. $5^{\text {th }}$ Ed. United States; Win. C. Brown.

Lamb, Charles; Hair, Joseph and Daneil, Carl. (1992). Principles of Marketing. $1^{\text {st }}$ Ed. USA: South Western Publication Company.

Lathey, B. Benjamin. (1998). Psychology. $6^{\text {th }}$ Ed. New Delhi: Tata Mc Graw Hill Publication Co. Ltd.

Martin, Brett. (2004). Using the imagination: Consumer evoking and thematizing of the fantastic imaginary. Journal of Consumer Research, 32 (2), 136-149.

Morris, G. Charles. (1993). Understanding Psychology. $2^{\text {nd }}$ Ed. New Jersey: Prentice Hall.

Petrova, Petia and Cialdini, Robert. (2005). Fluency of Consumption imagery and the backfire effects of imagery appeals. Journal of Consumer Research, 32 (3), 442-452.

Ramaswamy V.S. and Namakumari, S. (2002). Marketing Management. $3^{\text {rd }}$ Ed. New Delhi: Mac Millan India Ltd. Schewe, Charles. (1987). Marketing. $1^{\text {st }}$ Ed. USA: Random House.

Schiffman, Leon and Kanuk, Leslie. (2004). Consumer Behavior. $8^{\text {th }}$ Ed. USA: Prentice Hall.

Wright, Ray. (2000). Advertising. $1^{\text {st }}$ Ed. USA: Pearson Education Ltd. 
Appendix 1. Showing the Final List of 50 Advertising Attributes After Stage 3

\begin{tabular}{|c|c|}
\hline Joy & Illustrative \\
\hline Excitement & Relevancy \\
\hline Style & Perfect \\
\hline Uniqueness & Effective \\
\hline Believable & Persuasive \\
\hline Fun & Sensitive \\
\hline Fantasy & Inspiration \\
\hline Sex & Fascination \\
\hline Wonderful & Touchy \\
\hline Enthusiasm & Desirable \\
\hline Entertainment & Clarity \\
\hline Exclusiveness & Memorable \\
\hline Understanding & Intelligence \\
\hline Humor & Thinkable \\
\hline Creativity & Competency \\
\hline Product information & Credibility \\
\hline Attractiveness & Reputation \\
\hline Liveliness & Reality \\
\hline Interesting & Pomp \\
\hline Appreciation & Imagination \\
\hline Distinctiveness & Emotional \\
\hline Reliability & Energetic \\
\hline Beauty & Assertiveness \\
\hline Influential & Authenticity \\
\hline Well planned & Glamorous \\
\hline
\end{tabular}

Note: The advertising attributes have been presented in the random order. 
Appendix 2. Showing Item-Total Correlations for Bike $(\mathrm{N}=200)$

\begin{tabular}{|c|c|}
\hline Item name (characteristic) & Item-total correlation \\
\hline Excitement & .709956 \\
\hline Style & .759524 \\
\hline Fun & .305487 \\
\hline Fantasy & .302963 \\
\hline Wonderful & .307264 \\
\hline Enthusiasm & .225871 \\
\hline Creativity & .808927 \\
\hline Product information & .320518 \\
\hline Attractiveness & .861635 \\
\hline Liveliness & .834978 \\
\hline Interesting & .263301 \\
\hline Distinctiveness & .206755 \\
\hline Beauty & .73731 \\
\hline Well planned & .783392 \\
\hline Perfect & .244 \\
\hline Fascination & .253722 \\
\hline Desirable & .784588 \\
\hline Clarity & .824061 \\
\hline Memorable & .813939 \\
\hline Thinkable & .330951 \\
\hline Imaginative & .354482 \\
\hline Emotional & .260491 \\
\hline Energetic & .87207 \\
\hline
\end{tabular}

Note : The items are arranged in the random order. 
Appendix 3. Showing Final Statistics of Factors of Bike arrange

\begin{tabular}{|c|c|c|c|c|}
\hline Variable & Communality & Factor & Eigenvalue & Cum Pct \\
\hline VAR00001 & .45527 & 1 & 2.39221 & 10.4 \\
\hline VAR00002 & .71041 & 2 & 1.59139 & 17.3 \\
\hline VAR00003 & .40347 & 3 & 1.47642 & 23.7 \\
\hline VAR00004 & .58455 & 4 & 1.34338 & 29.6 \\
\hline VAR00005 & .58602 & 5 & 1.21363 & 34.9 \\
\hline VAR00006 & .59251 & 6 & 1.18892 & 40.0 \\
\hline VAR00007 & .55567 & 7 & 1.13809 & 45.0 \\
\hline VAR00008 & .40442 & 8 & 1.10222 & 49.8 \\
\hline VAR00009 & .59560 & 9 & 1.03582 & 54.3 \\
\hline VAR00010 & .53638 & & & \\
\hline VAR00011 & .51825 & & & \\
\hline VAR00012 & .63206 & & & \\
\hline VAR00013 & .58426 & & & \\
\hline VAR00014 & .39683 & & & \\
\hline VAR00015 & .58896 & & & \\
\hline VAR00016 & .71581 & & & \\
\hline VAR00017 & .57595 & & & \\
\hline VAR00018 & .52916 & & & \\
\hline VAR00019 & .53597 & & & \\
\hline VAR00020 & .53870 & & & \\
\hline VAR00021 & .48462 & & & \\
\hline VAR00022 & .46597 & & & \\
\hline VAR00023 & .49122 & & & \\
\hline
\end{tabular}

Appendix 4. Showing Final Statistics Of The Dimensions Of Bike

\begin{tabular}{|c|c|c|c|c|}
\hline Variable & Communality & Factor & Eigenvalue & Cum Pct \\
\hline VAR00001 & .76089 & 1 & 1.42435 & 15.8 \\
\hline VAR00002 & .70509 & 2 & 1.21892 & 29.4 \\
\hline VAR00003 & .51913 & 3 & 1.16321 & 42.3 \\
\hline VAR00004 & .72086 & 4 & 1.10079 & 54.5 \\
\hline VAR00005 & .76678 & 5 & 1.00909 & 65.7 \\
\hline VAR00006 & .49614 & & & \\
\hline VAR00007 & .87258 & & & \\
\hline VAR00008 & .80086 & & & \\
\hline VAR00009 & .27405 & & & \\
\hline
\end{tabular}


Appendix 5. First Order Factor Analysis for Factors of Bike

\begin{tabular}{|c|c|c|c|}
\hline S. no & Variable & Factor load & Factors \\
\hline 1 & Desire & 0.73482 & \multirow[t]{2}{*}{ Persuasiveness } \\
\hline 2 & Creativity & 0.49465 & \\
\hline 3 & Distinctiveness & 0.73378 & \multirow[t]{2}{*}{ Distinctiveness } \\
\hline 4 & Fantasy & 0.61291 & \\
\hline 5 & Perfect & 0.62717 & \multirow{3}{*}{ Perfectness } \\
\hline 6 & Well planned & 0.53859 & \\
\hline 7 & Fun & 0.49521 & \\
\hline 8 & Fascination & 0.80663 & \multirow[t]{2}{*}{ Fascinating } \\
\hline 9 & Excitement & 0.41482 & \\
\hline 10 & Wonderful & 0.64947 & \multirow[t]{2}{*}{ Sensational } \\
\hline 11 & Clarity & 0.63925 & \\
\hline 12 & Energy & 0.66775 & \multirow{4}{*}{ Energetic } \\
\hline 13 & Thinkable & 0.49604 & \\
\hline 14 & Imagination & 0.48748 & \\
\hline 15 & Product information & 0.48382 & \\
\hline 16 & Attractive & 0.66526 & \multirow{3}{*}{ Aesthetic } \\
\hline 17 & Memorable & 0.63120 & \\
\hline 18 & Liveliness & 0.62725 & \\
\hline 19 & Style & 0.68624 & \multirow[t]{2}{*}{ Elegant } \\
\hline 20 & Beauty & 0.68436 & \\
\hline 21 & Interesting & 0.64658 & \multirow{3}{*}{ Captivating } \\
\hline 22 & Emotional & 0.64345 & \\
\hline 23 & Enthusiastic & 0.54007 & \\
\hline
\end{tabular}

Appendix 6. Second Order Factor analysis for Dimensions

\begin{tabular}{|c|c|c|c|}
\hline S. no & Variable & Factor load & Dimension \\
\hline 1 & Energetic & 0.78011 & \multirow{2}{*}{ Energetic } \\
\hline 2 & Elegant & 0.51586 & \\
\hline 3 & Fascinating & 0.46528 & \multirow{2}{*}{ Sensational } \\
\hline 4 & Sensational & 0.66959 & \multirow{2}{*}{ Persuasive } \\
\hline 5 & Perfect & 0.65907 & Distinctness \\
\hline 6 & Persuasive & 0.88120 & Captivating \\
\hline 7 & Distinct & 0.92243 & \\
\hline 9 & Captivating & 0.81644 & 0.56030 \\
\hline
\end{tabular}


Appendix 7. Showing Mean Value of Male and Female as per the Factors

$\begin{array}{llll}\text { S. No } & \text { Factor } & \text { Mean } 1\left(\mathrm{X}_{1}\right) & \text { Mean 2 }\left(\mathrm{X}_{2}\right) \\ 1 & \text { Persuasiveness } & 1.75 & 1.71 \\ 2 & \text { Distinctness } & 0.30 & 0.52 \\ 3 & \text { Perfectness } & 1.11 & 1.25 \\ 4 & \text { Fascinating } & 0.93 & 0.1 \\ 5 & \text { Sensational } & 1.16 & 1.17 \\ 6 & \text { Energetic } & 3.64 & 3.59 \\ 7 & \text { Aesthetic } & 2.64 & 2.81\end{array}$

Appendix 8. Showing Mean Value of Male and Female as the Dimensions

$\begin{array}{llll}\text { S. No } & \text { Dimension } & \text { Mean 1 }\left(\mathrm{X}_{1}\right) & \text { Mean 2 }\left(\mathrm{X}_{2}\right) \\ 1 & \text { Energetic } & 6.11 & 6.27 \\ 2 & \text { Sensational } & 2.27 & 2.42 \\ 3 & \text { Persuasiveness } & 1.75 & 1.71 \\ 4 & \text { Distinctness } & 0.30 & 0.52\end{array}$

